\title{
ANALYSIS OF THE DEFORMATION PATTERN ALONG THE SUBDUCTION ZONE OF CRETE, GREECE, FROM MULTI-TEMPORAL ERS DATA
}

\author{
M. Kaskara ${ }^{(1)}$, A. Barberopoulou ${ }^{(1)}$, I. Papoutsis ${ }^{(1)}$, H. Kontoes ${ }^{(1)}$, A. Ganas ${ }^{(2)}$ and V. Karastathis ${ }^{(2)}$ \\ (1) National Observatory of Athens, Institute of Space Applications and Remote Sensing, Vas. Pavlou \& I. Metaxa, \\ 15236 Penteli, Greece,Email: mariakaskara@noa.gr,aggeliki@noa.gr,ipapoutsis@noa.gr,kontoes@noa.gr \\ (2) National Observatory of Athens, Institute of Geodynamics, Lofos Nymphon, 11810 Thissio, Athens, Greece, Email: \\ aganas@noa.gr,karastathis@gein.noa.gr
}

\begin{abstract}
Crete lies in the forearc basin of the collision zone between the Eurasian and African plates - one of the highest seismicity regions in the world.

The purpose of this study is to map ground deformation using time series analysis. Up until now, most geodetic observations used only GPS data. The key difference between space-based measurements and GPS or in-situ analysis is the good spatial coverage and the sensitivity of InSAR in the vertical direction.

Using Persistent Scatterers (PS) and Small Baseline Subset techniques, deformation maps of the entire island of Crete are produced for the first time and geophysical interpretation is provided. A significant uplift of +9 $\mathrm{mm} / \mathrm{yr}$ is observed at the centre of the island due to the subduction zone processes. Subsidence up to $-9 \mathrm{~mm} / \mathrm{yr}$ is also detected at Messara valley on the Southern part of central Crete, due to anthropogenic activities. A modelling approach was adopted to explain the deformation due to the subduction zone.
\end{abstract}

\section{INTRODUCTION}

Greece lies at the convergent boundary of the African and Eurasian plates. On a local scale the tectonics become complex with the existence of microplates such as the Aegean plate - extending over the central part of the Aegean sea - interacting with the Anatolian plate to the east. The subduction of the African plate underneath the Eurasian plate drives directly (megathrust along plate interface) or indirectly (upper plate) the seismicity of the region (Fig. 1).

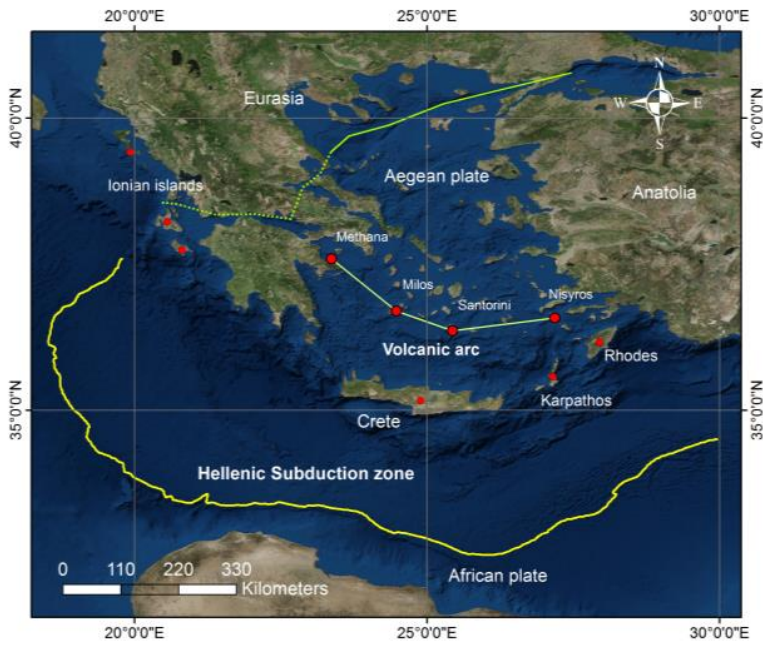

Figure 1. Map of the Aegean region showing the surface projection of the Hellenic arc, relative location of the Aegean and Anatolian plates and the volcanic and non-volcanic arc island.

The boundary between the Eurasian plate and the African plate is widely referred to as the Hellenic Arc. It is an arcuate tectonic feature of the Eastern Mediterranean Sea related to the subduction. It consists of an oceanic trench (Hellenic Trench), one volcanic arc (Aegean Volcanic Arc) and an inner non-volcanic arc. Two more ocean floor features define the tectonic processes of the region. The Hellenic Trench is a signature of the so-called forearc basin, the area between the volcanic arc and the surface expression of the subduction (Mediterranean ridge). Major characteristics of the subduction include E-W extension on the edges of its $1200 \mathrm{~km}$ length, variability in seismicity (focal mechanisms, depths of earthquakes) and N-S extension in the back-arc area ([1], [2]).

Crete is part of the non-volcanic arc that includes a number of other islands such as Rhodes and Karpathos to the east and the Ionian islands to the west (Fig. 1). This region is characterized by high seismicity (highest in Europe), it is capable of producing M8+ earthquakes, has been the source of great earthquakes in the past (i.e. $365 \mathrm{AD}$ western Crete, 1303AD eastern Crete) and is therefore of paramount importance in terms of seismic hazard. Vertical deformation observed on the island of Crete is primarily due to uplift associated with the plate 
convergence [1] while its horizontal motion with south to southwest direction is due to the interaction of the micro plates (Aegean, Anatolian) with the Eurasian and African plates.

Radar interferometry is a technique that has proven its capability to provide geodetic observations of anthropogenic and geodynamic processes. There are various papers studying subduction zones using InSAR observations [3, 4] and also an attempt to study the western part of Crete using Persistent Scatterers technique [5].

In this article, we present ground velocities for the entire island of Crete as obtained from the analysis of Synthetic Aperture Radar (SAR) imagery. In particular, deformation has been measured using three (3) tracks providing a near-complete geographic coverage of the island corresponding to around 85 ERS-1 and ERS-2 acquisitions from 1992 until 2001. Interferometric processing has been performed with the Stanford Method for Persistent Scatterers (StaMPS; [6]), complemented by the SARscape software.

Along with the observed large-scale deformation regime, associated with the subduction zone, local displacement patterns are also revealed attributed primarily to anthropogenic processes.

A modelling approach to explain the tectonic deformation observed in Crete is followed. Widely used Okada equations are used to estimate an annual slip rate at the plate interface and to model the uplift measured on Crete.

\section{STUDY AREA-TECTONIC SETTING}

The deformation observed on the island of Crete is largely a result of tectonic processes taking place over millions of years and is associated with the Hellenic Arc- the most seismogenic region in Europe. The Hellenic Arc is developing on the collision boundary of the Eurasian and African plates with a current convergence rate of $4-5 \mathrm{~cm} / \mathrm{yr}$. Reference [7] states that the active seismic front of the South Aegean subduction zone is located about $100 \mathrm{~km}$ offshore southern Crete.

Recent seismic studies show strong local variations in the tectonic setting of the island with extension and compression measured along Crete resulting in varying deformation patterns [7]. More specifically, profiles cutting across central Crete and running parallel to the island - were drawn from seismic reflection experiments to show complex faulting which can result in all types of earthquakes (focal mechanisms, depths etc.). It was suggested that a locally varying setting is responsible (Fig. 2). Many sources run offshore and onshore in the Aegean region. The largest sources (Length $>=30 \mathrm{~km}$ ) are shown in Fig. 2. There are many crustal faults which likely accumulate strain over long periods of time (w.r.t. human scale) but the deformation patterns studied in this article are largely associated with the subduction of the African plate beneath the Aegean region.

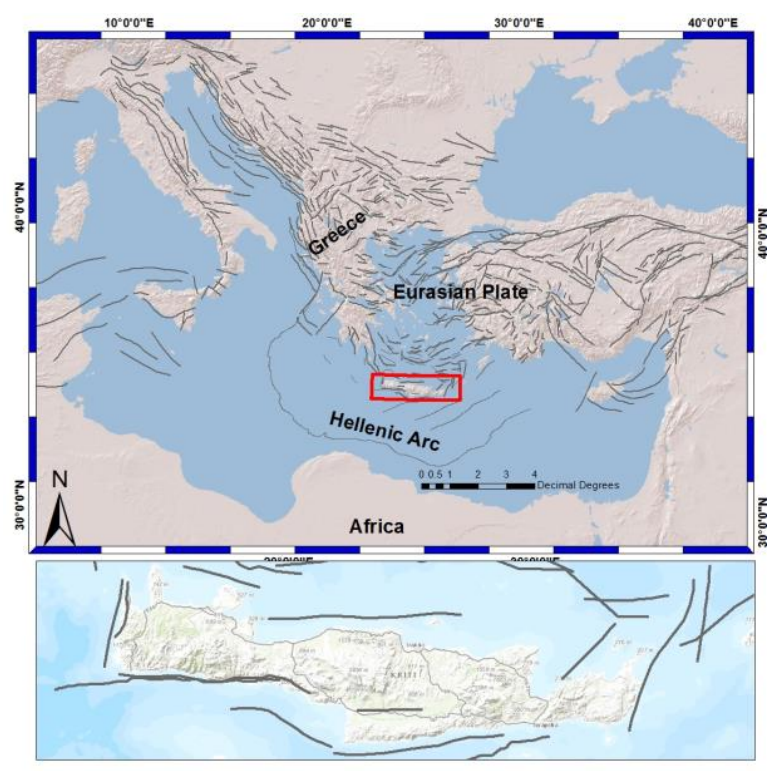

Figure 2. Fault sources map in Eastern Mediterranean and Greece. Inset shows our area of interest (red box).

Grey lines represent the largest faults in the Eastern Mediterranean region ( $L \geq 30 \mathrm{~km}),[8]$

\section{DATA AND PROCESSING}

Time series analysis is a well-established process employed in Spaceborne SAR Interferometry (InSAR) for the joint processing of $N$ SAR images in order to monitor changes induced by natural phenomena or human intervention covering an area of interest. For this study we have applied time series analysis techniques in the island of Crete to produce an annual deformation rate map based on a 10year-period dataset. Two of the most popular approaches are the method of Persistent Scatterers (PS) [9] and Small Baseline Subset (SBAS) techniques [10]. Both PS and SBAS techniques can be used to investigate phenomena which cause surface deformation due a geophysical process. The advantages of these techniques are the accuracy of the results at a millimeter level and the large spatial coverage capacity, achieving the equivalent of a very dense GPS network of permanent stations.

All available scenes of ERS1 and ERS2 data were acquired and processed in order to monitor crustal deformation associated with the island of Crete during the period 1992-2001. The Persistent Scatterer Interferometry processing was performed with the opensource and commercial software, namely Doris, ROI_PAC, StaMPS [6] and SARscape (an add-on module of $\mathrm{ENVI}^{\mathrm{TM}}$ ). In this article we present results as obtained from StaMPS/MTI (Stanford Method for Persistent Scatterers; Multi-Temporal InSAR), a software package that implements not only the PS method but also a small baseline and a combined multitemporal method [11]. 


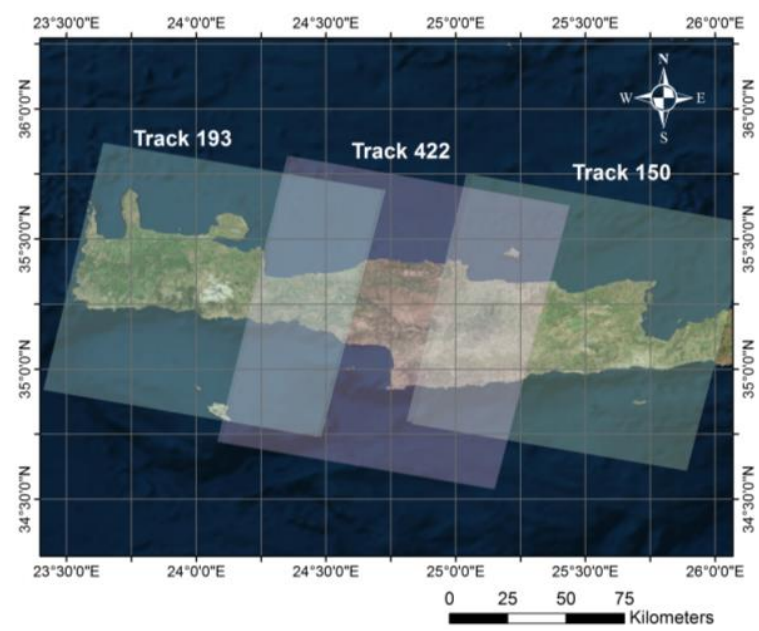

Figure 3. Tracks of ERS1-2 satellites covering the island of Crete

Thirty five (35) descending acquisitions of track 193, twenty one (21) descending acquisitions of track 422 and twenty eight (28) descending acquisitions of track 150 spanning the period between 1992 and 2001 were used (Fig. 3). From each set of the acquisitions (per track) a master image was selected according to minimization of perpendicular and temporal baseline criteria. The tracks cover nearly the complete island of Crete except for the easternmost end of the island.

Topographic errors were corrected with the use of a Digital Elevation Model (DEM) of $5 \mathrm{~m}$ spatial resolution obtained from the National Cadastral and Mapping Agency SA., oversampled to $20 \mathrm{~m}$ to fit the resolution in SAR images (Fig. 4).

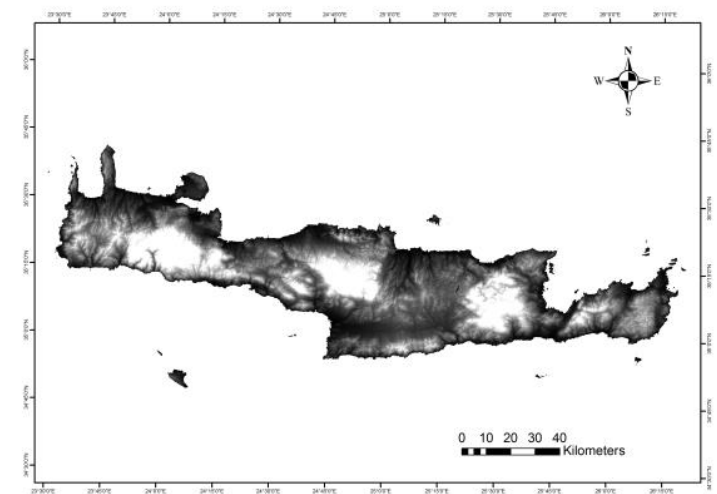

Figure 4. Digital Elevation Model of the island of Crete

At first, the StaMPS PS processing was applied. Using the PS method, the master image was combined with all remaining images (also referred to as the slave images) to generate $N-1$ interferograms. A master image is usually selected as the image that minimizes the average temporal and spatial baselines. The PS method exploits the phase and the amplitude characteristics of interferometric pairs to select the stable pixels or otherwise called persistent scatterers that have unchanged backscattering characteristics, such as is the case with structures i.e. roads, dams, bridges etc.

The ERS Crete data set was also processed with the StaMPS SBAS method. The SBAS technique is based on a suitable combination of interferograms which are characterized by small spatial, Doppler and temporal baselines. Image pairs were selected on the basis of a minimum coherence of 0.5 , aiming at mitigating strong decorellation contributions and as a result the overall coherence is maximized. In Fig. 4, the baseline plots for all the tracks are shown.
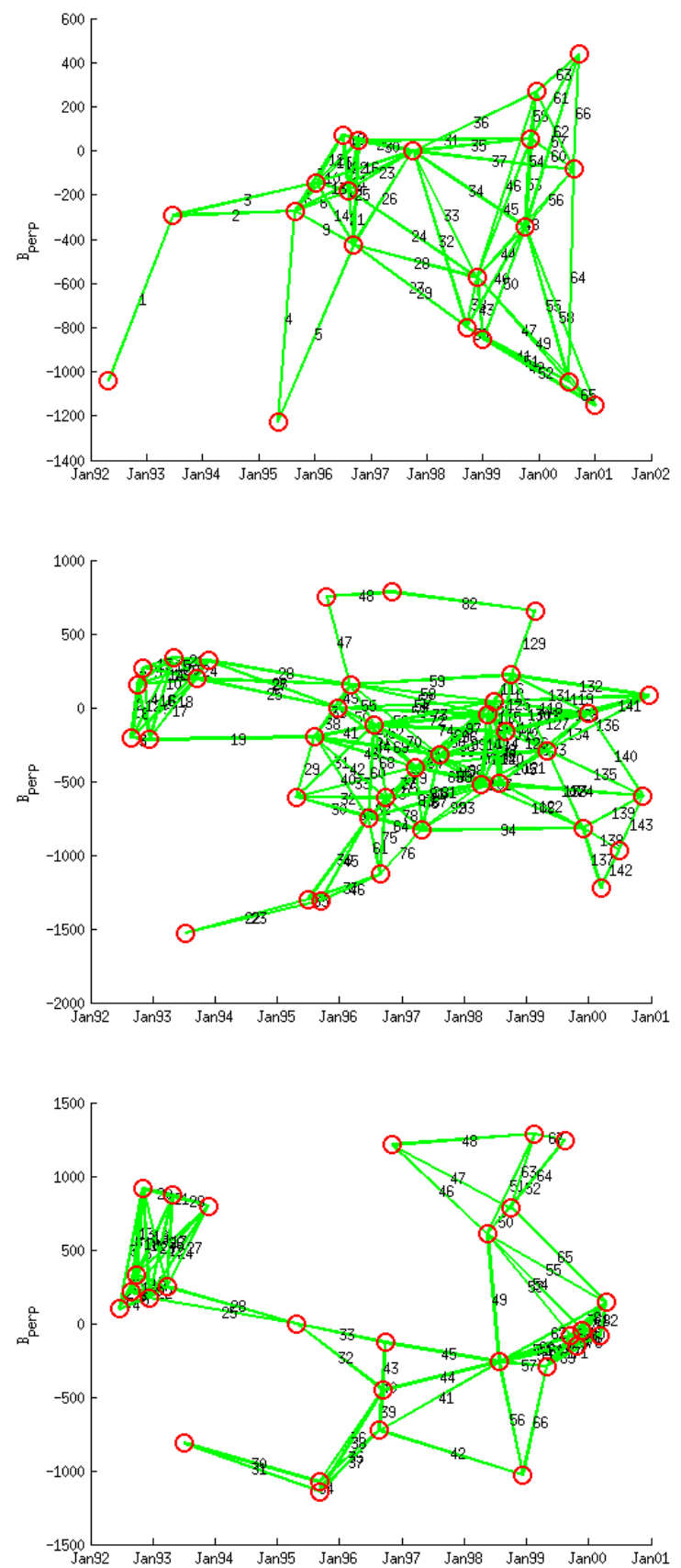

Figure 5.Baseline plots. Upper: track 193. Middle: track 422. Lower: track 150. Circles represent the images. The green lines represent the interferograms used in the processing 
Subsequently, we apply the combined (PS+SBAS) MTI processing scheme of StaMPS software to increase the spatial sampling of the coherent pixels. The advantage of this technique is that the combination of points from the two techniques applied prior to the phase unwrapping step, results in obtaining more stable-phase pixels, therefore reducing phase unwrapping errors [11]. Tab. 1 contains a summary of the data for each track such as the number of images, the selected master image, the number of the selected PSs, the number of coherent pixels during the SBAS technique as well as the selected stable area in which all velocities are referred to.

Table 1. Information for the processing of ERS1-2 ASAR data

\begin{tabular}{|l|l|l|l|}
\hline Info Track & $\mathbf{1 9 3}$ & $\mathbf{4 2 2}$ & $\mathbf{1 5 0}$ \\
\hline $\begin{array}{l}\text { Number of } \\
\text { acquisitions }\end{array}$ & 35 & 21 & 28 \\
\hline Master Image & 19951225 & 19971001 & 19940420 \\
\hline PS & 209,668 & 333,602 & 127,745 \\
\hline $\begin{array}{l}\text { SBAS } \\
\text { interferometric } \\
\text { pairs }\end{array}$ & 143 & 61 & 82 \\
\hline $\begin{array}{l}\text { SBAS coherent } \\
\text { pixels }\end{array}$ & 139,466 & $\mathrm{n} / \mathrm{a}$ & 102,590 \\
\hline $\begin{array}{l}\text { Combined PS and } \\
\text { SBAS pixels }\end{array}$ & 345,445 & $\mathrm{n} / \mathrm{a}$ & 222,281 \\
\hline $\begin{array}{l}\text { Reference area } \\
\text { latitude longitude } \\
\text { (degrees) }\end{array}$ & $24.0177 \mathrm{~N}$ & $25.1521 \mathrm{~N}$ & $25.1521 \mathrm{~N}$ \\
\hline $\begin{array}{l}\text { Reference area } \\
\text { radius (meters) }\end{array}$ & 100 & $35.3289 \mathrm{E}$ & $35.3289 \mathrm{E}$ \\
\hline
\end{tabular}

For track 422, we relied solely on the PS processing technique because it gave us enough coherent pixels with a quite low standard deviation and high spatial density.

A really important part of the processing is the selection of the reference point. As stable -reference area, for the track 193 we selected an area around GPS station "CHAN" of the Greek Network with a radius of 100 meters (Fig. 6). For the tracks 422 and 150, an area at Heraklion city "AS13" was selected (Fig. 7, 9). These areas were selected on the following basis: a) they are located in bedrock (i.e. limestone) and b) the GPS data indicate stability on the vertical component (i.e. they are confined in the range -1.0 to $1.0 \mathrm{~mm} / \mathrm{yr}$ ).

\section{RESULTS}

Fig. 6, 7 and 9 show the results of the processing for each one of the three tracks.

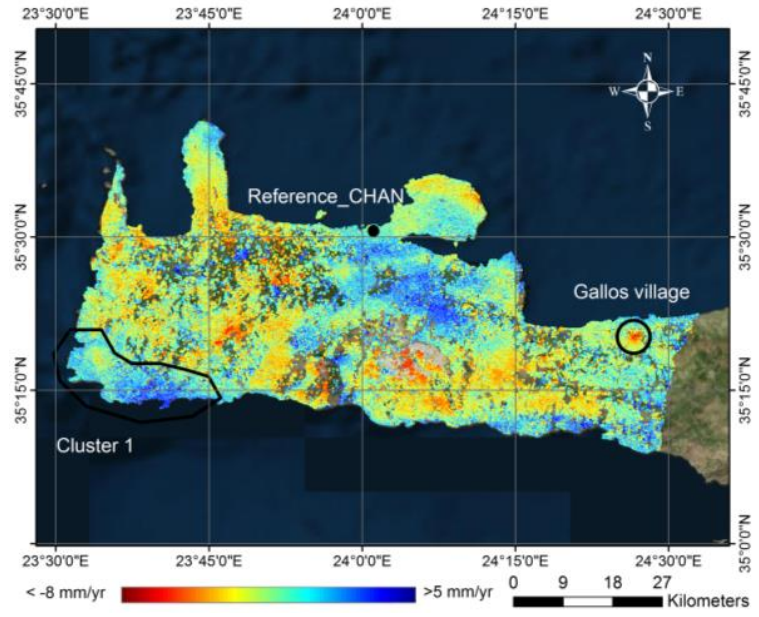

Figure 6. Velocities for West Crete as estimated by StaMPS/MTI - Track 193. Black line encircles areas of strong uplift or subsidence

At track 193 (Fig. 6), an area of uplift at South-Western Crete stands out (Cluster 1) with average velocity of $\sim 5$ $\mathrm{mm} / \mathrm{yr}$. This area of uplift is believed to be associated with the subduction tectonic regime and agrees with similar studies [5]. This area is composed mostly of bedrock, it is characterised by high relief and limited human activities. Furthermore, there is abundant geological evidence for coastal uplift [12].

Gallos village on the edge of track 193 (Fig. 6), has been identified as an area of possible subsidence $(-4$ $\mathrm{mm} / \mathrm{yr}$ ). In 1996, the University of Crete (UoC) took over land in this region. Construction to enhance the land that now hosts the UoC campus may have resulted in surface subsidence. This case needs further investigation, as there is no known history of deformation in this area -to the best of our knowledge.

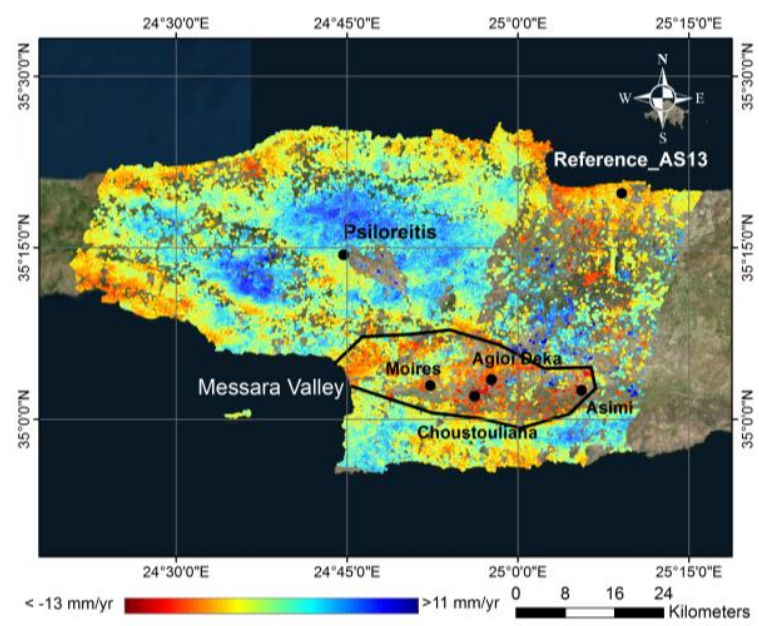

Figure 7. Velocities for Central Crete as estimated by StaMPS/MTI - Track 422. Black line indicates area of prominent deformation. 
The outcome of the combined MTI processing of track 422 shows uplift in central Crete (in the area of Psiloreitis Mountain) coloured blue in Fig. 7. The area is uplifting with a velocity up to $9 \mathrm{~mm} / \mathrm{yr}$. This deformation pattern is believed to be related to the convergence of the African plate to Eurasia leading to pushing the island upwards. Although a thorough physical explanation of these vertical movements is beyond the scope of this work, this behaviour may be explained by on-going tectonic activity (e.g. a subduction-related earthquake cycle) in the Hellenic subduction zone.

The most prominent subsidence area identified from the interferometric processing is located at central Crete southeast of Psiloreitis mountain- in the Messara Valley (Fig. 7). Messara Valley is an E-W extending formation known as graben, bounded by normal faults [13].

The valley is used for intense agricultural purposes (Fig. 8 ) and heavy water extraction for irrigation purposes has dramatically lowered the water level in aquifers. The areas that show the greatest subsidence, up to $9 \mathrm{~mm} / \mathrm{yr}$, are "Asimi", "Moires", "Choustouliana" and "Agioi Deka" (Fig. 7, 9). Land subsidence in Messara Valley has also been measured in recent studies using the conventional DInSAR technique for the time interval 1992-2000 [14].

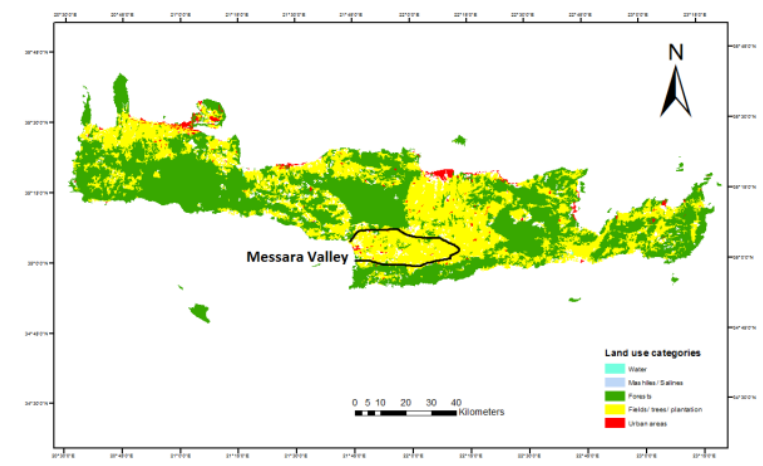

Figure 8. Land use of Crete, Black line indicates Messara Valley

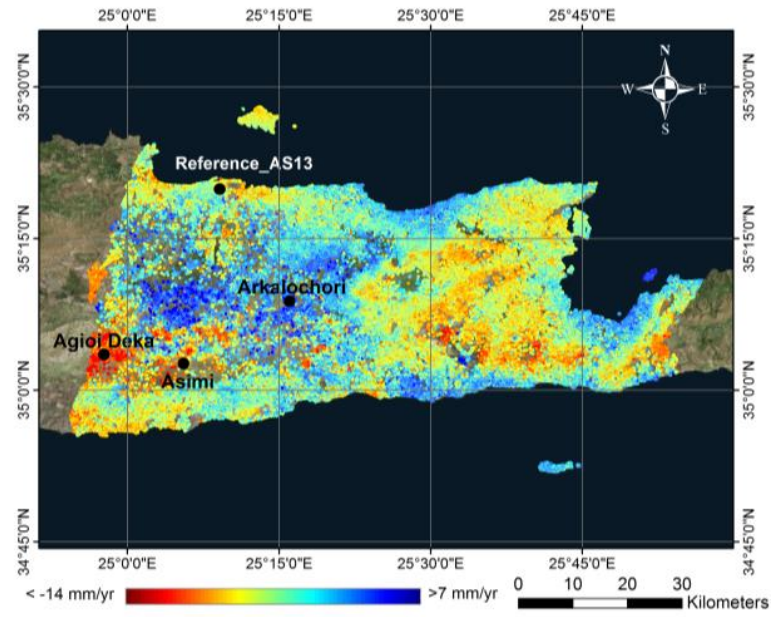

Figure 9. Velocities for Eastern Crete as estimated by StaMPS/MTI - Track 150

The easternmost part of the island shows both uplift and subsidence (Fig. 9) "Asimi" and "Agioi Deka" villages in the Messara Valley, show subsidence - reaching 9 $\mathrm{mm} / \mathrm{yr}$, similar to what we observed from track 422 . It needs to be noted that these areas are in the overlap area of two tracks. "Arkalochori" village shows the most significant uplift up to $6 \mathrm{~mm} / \mathrm{yr}$ in this track (150).

Fig. 10 correlates the results for the entire island with known faults near the area of interest. The overlapping areas between tracks $193 \& 422$ and $422 \& 150$ provided a good opportunity for validation of the results. Velocity values appear to be of similar magnitude from both tracks. For the construction of Fig. 10, all 3 tracks were combined. In the overlapping regions we only used the points which have the lowest standard deviation from the two overlapping tracks.

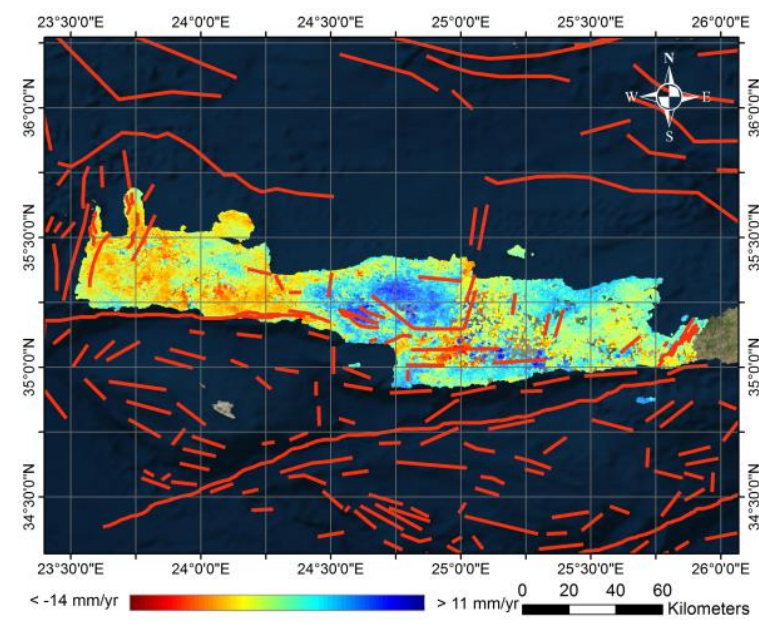

Figure 10. Velocities as obtained from STAMPS/MTI processing for the entire island of Crete. Red lines depict known faults on or near the island of Crete. 


\section{MODELING APPROACH}

The final goal of this work is to use the results obtained from the time series processing in order to understand the tectonic processes which produce them. There are various modelling approaches one can adopt to explain the measured velocities. Our methodology is explained below and the main idea is similar to studies which model deformation due to an earthquake $[15,16]$. The main differences with modelling earthquake induced deformation and the deformation we show in this article are:

1. Data used are velocities as opposed to displacement.

2. Tectonic process cannot be considered instantaneous as is the case in co-seismic measurements.

3. Deformation is more prominent from an earthquake than that measured from motions associated with the collision of two plates.

To understand the assumptions made for this problem we need to place the continuous deformation observed in the context of the seismic cycle. There are four stages associated with the so-called seismic cycle:

- co-seismic (associated with an earthquake)

- post-seismic (return of material following an earthquake to a state of balance).

- $\quad$ pre-seismic (preceding an earthquake)

- interseismic (period between large earthquakes). This is important especially in large zones of deformation i.e. subduction zones because it is the period leading to rupture.

The deformation that we try to explain in Crete belongs to the interseismic cycle and is the large driving mechanism behind the deformation measured on the island (i.e. uplift). The model of subduction that our methodology is based on, attributes strain accumulation and release at a subduction zone to a locked (no slip) zone [16]. Basically if the overriding plate (Aegean) was moving in an ideal fashion - past the African plate no deformation on the island of Crete would be observed. This represents a steady state. Any strain accumulation as that which results in the velocities we measure from satellites, are due to perturbations from this state due to the no slip condition at the plate interface.

The main steps in explaining surface deformation due to subduction involves the following:

1. Processing of satellite data to acquire velocities on the ground.

2. Inverting of velocities to provide the slip rate at the plate interface.

\subsection{Interseismic Linear Modelling}

Linear inversion is performed to retrieve the distribution of slip rate (interseismic) over the fault, assuming a fixed geometry (Tab. 2). For this application we have used commercial software SARscape [17]. SARscape contains a modelling module in addition to the processing tools for SAR images. This module has been a later addition to the commercial software and has been developed with modelling deformation related to earthquakes, subduction, sinkholes or volcanic activity. It implements Okada dislocation model which describes surface deformation associated with rectangular dislocations of arbitrary orientation within a purely elastic half space [15]. The interseismic deformation as the one observed in Crete involves long term monitoring (decades) and smaller motions than those associated with large earthquakes (M6+).

For the purpose of modelling we have assumed the plate interface to be known from the most-up-to-date geological, seismological or other relevant studies $[1,7$, 18]. These recent investigations on the crustal structure of the Hellenic Subduction zone show variation in subduction (shallow dipping to deep) of the African plate as one moves north. The part of the subduction responsible for the shortening of the crust in Crete extends from $30 \mathrm{~km}$ depth to about $100 \mathrm{~km}$ dipping at 30 degrees. Due to uncertainties in the exact location of the plate interface three small variations were tried on the location of the interface (moving source to the south and varying the dip angle). We also used two different strike angles to better resemble the Hellenic arc curvature. The other two surfaces (Case B and Case C) were placed at $34.5 \mathrm{~N}$ and $34 \mathrm{~N}$ using a dip angle of 20 and 15 degrees correspondingly. We present results for Case A-the northernmost fault surface used (geometry is described below):

Table 2. Geometry of the fault surface used in linear

\begin{tabular}{|c|c|c|c|c|c|c|}
\hline $\begin{array}{c}\text { Length } \\
(\mathrm{km})\end{array}$ & $\begin{array}{c}\text { Width } \\
(\mathrm{km})\end{array}$ & $\begin{array}{c}\text { Strike } \\
(\mathrm{deg})\end{array}$ & $\begin{array}{c}\text { Dip } \\
(\mathrm{deg})\end{array}$ & $\begin{array}{c}\text { Rake } \\
(\mathrm{deg})\end{array}$ & Lat & Lon \\
\hline 200 & 100 & 270 & 30 & 90 & $35 \mathrm{~N}$ & $25 \mathrm{E}$ \\
\hline
\end{tabular}

Using the fault geometry described in Tab. 2 we run a linear inversion to estimate the interseismic slip rate (Fig. 11). The preliminary slip rate distribution map shows that a region underneath Crete of stick slip motion is responsible for the uplift we observe in Central Crete (compare Fig. 7 to Fig. 11). The slip rate distribution appears to explain fairly well the circular deformation pattern obtained from the time series processing (Fig. 12). 


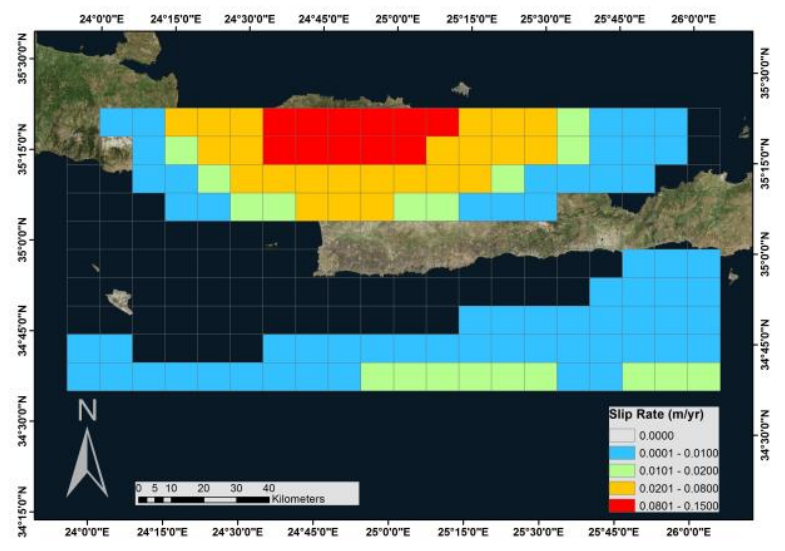

Figure 11. Interseismic slip rate distribution as obtained from the linear inversion for the Island of Crete assuming 'Case A' fault geometry.

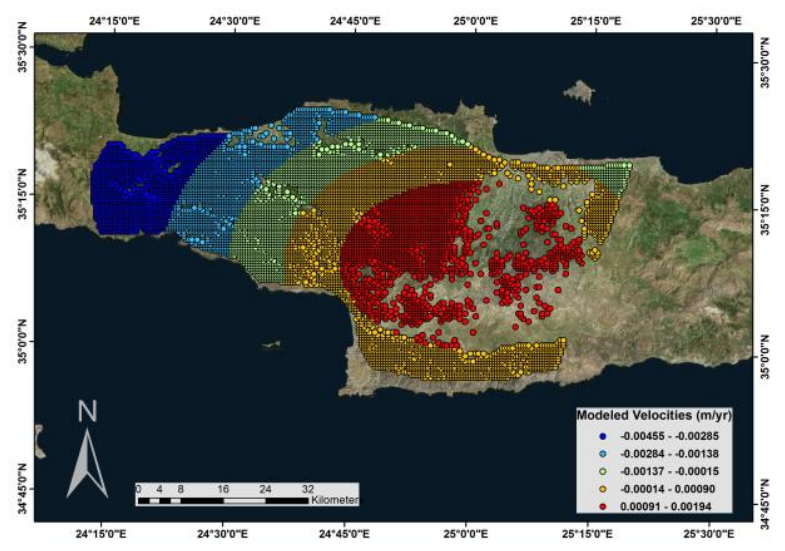

Figure 12. Modelled velocities over central Crete.

Slip rate values are reasonable but much larger than the plate convergence rate. Such values could be further refined with better constraints on the fault surface. We use a simple model of elastic deformation assuming a homogeneous material and no topography. The latter contribution has not been investigated. The velocity measurements are distributed on the northern end of the surface projection of the fault interface leading to poor constraint of the slip rate especially in those cases where the source is further south (Case B and Case C).

\section{CONCLUSIONS AND FUTURE WORK}

Time series analysis is a promising and powerful tool that has been developed over the last decades to produce Line of Sight (LOS) ground deformation maps.

In this study, PS and SBAS approaches were used to measure deformation on the island of Crete. Velocities indicate a large uplift trend of up to $9 \mathrm{~mm} / \mathrm{yr}$ at the centre of the island due to shortening caused by the collision of the two plates. In addition, high subsidence rates of $-9 \mathrm{~mm} / \mathrm{yr}$ are observed at Messara basin due to groundwater withdrawal. Some of the deformation observed on the island of Crete can be well explained by anthropogenic processes taking place however the tectonic deformation needs to be investigated further. Further work is currently in progress for the estimation of velocities during the time period 2001-2010 with ENVISAT data. Additionally, the correlation of the MTI results with GPS measurements will be included in future work. We aspire to combine the high spatial resolution of SAR technique with the high temporal resolution that GPS technology offers. Our goal is to compare the displacement rates with GPS measurements on the island, in order to validate the SAR deformation rates and monitor potential variations in velocities.

A first attempt to estimate slip rates on the plate interface of the subduction zone has been introduced. Three different cases were used to investigate the slip rate distribution due to uncertainties in the location of the plate interface beneath Crete. For each of the three cases the fault was represented as one uniform surface divided in equal width-and-length patches $(10 \mathrm{~km} \mathrm{x}$ $10 \mathrm{~km}$ ) varying only the dip angle and the location of the source. Another case where strike of the surface beneath Western Crete changed was also attempted. During this preliminary investigation we found that due to the velocities being distributed on the island of Crete and on the northernmost end of the surface projection of the plate interface, slip rate cannot be well constrained in some of the cases (Case B and Case C). The circular pattern, characteristic of the uplift observed on Central Crete is resolved well even by our simple model but the velocities are underestimated.

This work is far from complete and better constraints of the plate interface as well as the locked zone need to be made. The Okada equations are widely used and may offer an approximation of the hazard to first order however, we need to keep in mind that a number of assumptions have been made including a homogeneous material makeup for the subsurface and an elastic model to explain deformation on the surface due to small motions on a fault at depth. The inclusion of topography in the results has not been investigated at this point. Slip rate distribution maps have great potential as can be used to map future ruptures and therefore directly correspond to seismic hazard.

\section{ACKNOWLEDGMENTS}

We would like to thank the European Space Agency for the provision of the SAR data and the staff of the sarmap team: Alessio Cantone and Simone Atzori for their help and valuable feedback in the processing of ERS1-2 images and also with the modelling module of SARscape.

The work was supported by the European Union Seventh Framework Programme (FP7-REGPOT-20122013-1), in the framework of the project BEYOND, under Grant Agreement No. 316210 (BEYOND Building Capacity for a Centre of Excellence for EObased monitoring of Natural Disastershttp://www.beyond-eocenter.eu). 
Active faults map was provided by the Institute of Geodynamics of the National Observatory of Athens.

\section{REFERENCES}

1. Ganas, A. \& Parsons, T. (2009). Three-dimensional model of Hellenic Arc deformation and origin of the Cretan uplift. J. Geophysical Research, 114, B06404.

2. Becker, D., Meier, T., Bohnhoff, M. \& Harjes, H.-P. (2010). Seismicity at the convergent plate boundary offshore Crete, Greece, observed by an amphibian network. Journal of Seismology, 14, 2, p. 369-392.

3. Chlieh, M., de Chabalier, J. B., Ruegg, J. C., Armijo, R., Dmowska, R. \& Campos, J. (2004). Crustal deformation and fault slip during the seismic cycle in the North Chile subduction zone, from GPS and InSAR observations. Geophysical Journal, Volume 158, Issue 2, pp. 695-711.

4. Bekaert, D., Hooper, A., Pathier, E. \& Yun, S. (2010). InSAR time series analysis of the 2006 slow slip event on the Guerrero Subduction Zone, Mexico. AGU Abstract.

5. Riegler, S., Adam, N. \& Friedrich, A. M. (2012). Quantification of crustal deformation based on analysis of Persistent Scatterer Interferometry of W-Crete. EGU General Assembly 2012.

6. Hooper, A., P. Segall, and H. Zebker (2007), Persistent Scatterer InSAR for Crustal Deformation Analysis, with Application to Volcán Alcedo, Galápagos, J. Geophysical Research, 112, B07407.

7. Bohnhoff, M., Makris, J., Papanikolaou, D. \& Stavrakakis, G. (2001). Crustal investigations of the Hellenic subduction zone using wide aperture seismic data. Tectonophysics, 343, 239-262.

8. Basili R., et al., (2013). The European Database of Seismogenic Faults (EDSF) compiled in the framework of the Project SHARE. http://diss.rm.ingv.it/share-edsf/.

9. Ferretti, A., Prati, C. \& Rocca, F. (2001). Permanent scatterers in SAR interferometry. IEEE Trans. Geosci. Remote Sens., 39(1), pp. 8-20.

10. Berardino, P., Fornaro, G., Lanari, R. \& Sansosti, E. (2002). A new algorithm for surface deformation monitoring based on small baseline differential SAR interferograms. IEEE Trans. Geosci. Remote Sens., 40 (11), pp. 2375-2383.

11. Hooper, A. (2008). A multi-temporal InSAR method incorporating both persistent scatterer and small baseline approaches. Geophysical Research Letters, 35, L16302.
12. Tiberti, MM., Basili, R. \& Vannoli, P. (2014). Ups and downs in western Crete (Hellenic subduction zone). Scientific reports, 4: 5677.

13. Vassilakis, E. (2006). Study of the tectonic structure of Messara basin, central Crete, with the aid of remote sensing techniques and GIS. PhD Thesis, National \& Kapodistrian University of Athens.

14. Mertikas, S. P., Papadaki, E. S. \& Paleologos, Ev. (2009). Radar Interferometry for Monitoring Land Subsidence due to over-pumping Ground Water in Crete, Greece. Proceedings of the Fringe Workshop, Frascati, Italy, p. 4.

15. Okada, Y. (1992). Internal deformation due to shear and tensile faults in a half-space. Bull. Seismol. Soc. Am., 82, 1018 - 1040.

16. Savage, J. C. (1983). A dislocation model of strain accumulation and release at a subduction zone. $J$. Geophys. Res., 88, 4984-4996.

17. Atzori, S., Manunta, M., Fornaro, G., Ganas, A. \& Salvi, S. (2008). Postseismic displacement of the 1999 Athens earthquake retrieved by the differential interferometry by synthetic aperture radar time series. J. Geophyical. Research, vol. 113, pp.B09309.

18. Papazachos, C.B., Karakostas, V.G., Papazachos, C.B. \& Scordilis, E.M. (2000). The geometry of the Wadati-Benioff zone and lithospheric kinematics in the Hellenic arc, Tectonophysics, 319(4), 275-300. 